\title{
Chitosan Scaffolds Containing Hyaluronic Acid for Cartilage
}

\section{Tissue Engineering}

Clara Correia, MSc ${ }^{1,2}$, Liliana S. Moreira-Teixeira, MSc ${ }^{3}$, Lorenzo Moroni, Ph.D. ${ }^{3}$, Rui L. Reis, Ph.D. ${ }^{1,2}$, Clemens A. Van Blitterswijk, Ph.D. ${ }^{3}$, Marcel Karperien, Ph.D. ${ }^{3}$, and João F. Mano, Ph.D. $1,2, *$

1 3B's Research Group - Biomaterials, Biodegradables and Biomimetics, University of Minho, Headquarters of the European Institute of Excellence on Tissue Engineering and Regenerative Medicine, AvePark, 4806-909 Taipas, Guimarães, Portugal.

2 IBB - Institute for Biotechnology and Bioengineering, PT Associated Laboratory, Guimarães, Portugal.

${ }^{3}$ MIRA - Institute for BioMedical Technology and Technical Medicine, Twente University. Department of Tissue Regeneration, P.O. Box 217, Enschede 7500 AE, The Netherlands.

*Corresponding author.

Clara Correia: (a) Address: 3B's Research Group - Biomaterials, Biodegradables and Biomimetics, AvePark, Zona Industrial da Gandra, S. Cláudio do Barco, 4806-909 Caldas das Taipas, Guimarães, Portugal (b) TEL.: +351253510904, (c) Fax: +351253510909 (d) E-mail: clarasilvacorreia@gmail.com

Liliana S. Moreira-Teixeira: (a) Address: Address: University of Twente, Faculty Science \& Technology, Institute for Biomedical Technology \& Technical Medicine (MIRA), Zuidhorst ZH134, 
Drienerlolaan 5, 7522 NB Enschede, the Netherlands (b) (b) TEL.: +31-(0)53-489-3124 (c) Fax: +31-(0)53-489-2150 (d) E-mail: L.S.MoreiraTeixeira@tnw.utwente.nl

Lorenzo Moroni: (a) Address: University of Twente, Faculty Science \& Technology, Institute for Biomedical Technology \& Technical Medicine (MIRA), Zuidhorst ZH147, Drienerlolaan 5, 7522 NB Enschede, the Netherlands (b) TEL.: +31-(0)53-489-3502/3400 (c) Fax: +31-(0)53-489-2150 (d) E-mail: 1.moroni@utwente.nl

Rui L. Reis: (a) Address: 3B's Research Group - Biomaterials, Biodegradables and Biomimetics, AvePark, Zona Industrial da Gandra, S. Cláudio do Barco, 4806-909 Caldas das Taipas, Guimarães, Portugal (b) TEL.: +351253510904, (c) Fax: +351253510909 (d) E-mail: rgreis@ dep.uminho.pt

Clemens A. van der Bitterswijk: (a) Address: Department of Tissue Regeneration, University of Twente / Faculty Science \& Technology, Institute for Biomedical Technology, Zuidhorst ZH136, Drienerlolaan 5, 7522 NB Enschede, the Netherlands (b) TEL.: +31-(0)53-489-3400 (c) Fax: +31-(0) 53-489-2150 (d) E-mail: c.a.vanblitterswijk@utwente.nl

Marcel Karperien: (a) Address: Department of Tissue Regeneration, University of Twente / Faculty Science \& Technology, Institute for Biomedical Technology, Zuidhorst ZH144, Drienerlolaan 5, 7522 NB Enschede, the Netherlands (b) TEL.: +31 (0) 534893323 /3400 (c) Fax: +31 (0) 53489 2150 (d) E-mail: H.B.J.Karperien@tnw.utwente.nl 


\begin{abstract}
Scaffolds derived from natural polysaccharides are very promising in tissue engineering applications and regenerative medicine, as they resemble glycosaminoglycans in the extracellular matrix. In this study we have prepared freeze-dried composite scaffolds of chitosan (CHT) and hyaluronic acid (HA), in different weight ratios containing either no HA (control), $1 \%, 5 \%$, or $10 \%$ of $\mathrm{HA}$. We hypothesized that HA could enhance structural and biological properties of chitosan scaffolds. To test this hypothesis, physicochemical and biological properties of CHT/HA scaffolds were evaluated. SEM micrographs, mechanical properties, swelling tests, enzymatic degradation, and FT-IR chemical maps were performed. To test the ability of the CHT/HA scaffolds to support chondrocyte adhesion and proliferation, live-dead and MTT assays were performed. Results showed that CHT/HA composite scaffolds are non-cytotoxic and promote cell adhesion. ECM formation was further evaluated with safranin-O and alcian blue stainings, and GAG and DNA quantifications were performed. The incorporation of HA enhanced cartilage ECM production. CHT/5HA had a better pore network configuration and exhibited enhanced ECM cartilage formation. Based on our results we believe that CHT/HA composite matrixes have potential use in cartilage repair.
\end{abstract}

Keywords: chitosan, hyaluronic acid, scaffold, chondrocyte, cartilage tissue engineering. 


\section{Introduction}

Cartilage damage frequently occurs due to sports or progressive ageing. Once damaged, cartilage cannot be spontaneously repaired because of its avascularity and low cellular mitotic activity [1]. A range of clinical options emerged to repair focal lesions and damage to the articular surface. These approaches may reduce pain and increase mobility, but only to a limited extent and over a short-term period $[2,3]$. Current strategies are not able to fully restore the native structure of cartilage which raises concerns about the long term performance of repaired cartilage [4]. These partial successes lead to significant research efforts to develop tissue engineering therapies for cartilage repair.

The main challenge for cartilage tissue engineering is the chondrocytes massive transition into fibroblastic cells during the in vitro culture process. Those de-differentiated cells form fibrocartilage instead of hyaline cartilage [5]. Additionally, chondrocytes availability is limited due to the size of biopsies that can be collected from the patient's own tissue, without causing the risk of morbidity of the site of explant. Moreover, the development of biodegradable polymers to perform the role of a temporary matrix is an important factor in the success of cell transplantation $[6,7]$.

Extracellular matrices (ECMs) provide a microenvironment for cells to maintain homeostasis and to retain the required differentiated state for specific tissues [8]. Among the many different ECM molecules, hyaluronic acid (HA) is the main glycosaminoglycan (GAG) in the mesenchyme during the early stage of chondrogenesis $[9,10]$. In addition, HA is known to influence chondrocytes by triggering a sophisticated signaling pathway leading to enhancement of cellular functions [11, 12]. However, the concentration of HA must be confined to a relatively low amount, since concentrations may reduce cell adhesion due its negative charge [13]. This disadvantage can be overcome by combining HA with positively charged polycations such as chitosan [14]. Chitosan (CHT), a partially deacetylated derivative from chitin, has the ability to interact with negatively charged molecules [15]. Due to its biocompatibility and biodegradability, chitosan has been widely applied in tissue engineering strategies [16-19]. Additionally, chitosan is structurally similar to various GAGs 
found in articular cartilage [20]. Combining the advantages of both polysaccharides, CHT/HA scaffolds can be suitable candidates for cartilage tissue regeneration. The blend would be stabilized due to an ionic interaction between the positively charged chitosan and the negatively charged hyaluronic acid.

Chitosan has already been conjugated with hyaluronic acid to obtain a biomimetic matrix for chondrocytes [16, 21-24]. Yamane et al. [22] developed chitosan-based hyaluronic acid polymer fibers by the wetspinning method. In the hybrid fibers, chondrocyte adhesion, proliferation, and also the synthesis of aggrecan and type II collagen, were significantly higher comparing to chitosan fibers. Hsu et al. [24] studied chitosan-alginate-hyaluronan scaffolds, with or without covalent attachment, with RGD containing protein. The cell-seeded scaffolds showed neocartilage formation in vitro in the presence or absence of RGD. Tan et al. [21] demonstrated that chitosan-hyaluronic acid hydrogels allowed cell survivor, and cells retained the chondrogenic morphology.

The reported studies are focused on the superior biological effects that HA could provide, and its incorporation has not been studied in terms of physicochemical effects. Additionally, to our knowledge, the effect of varying the ratio between chitosan and hyaluronic acid, and, consequently, its influence in terms of both physicochemical and biological properties, has not been yet reported. On the other hand, due to HA high water uptake and the lack of mechanical strength provided by natural polymers, the existing strategies combining CHT and HA for cartilage tissue engineering are very limited and usually consist in hydrogels [21, 25]. However, these hydrogels do not have the required mechanical strength to maintain the initial shape of the implanted scaffold. Consequently, they cannot be transplanted into large cartilaginous lesions in advanced degenerative diseases, such as osteoarthritis and rheumatoid arthritis. Moreover, the existing CHT/HA blends are usually used to produce scaffolds by techniques more complexes than the freeze-drying method, in which further research is needed to determine the adequate shape, pore size, and mechanical properties of a 3D fabrication for cartilage TE. 
The aim of this work was to prepare a new class of hybrid scaffolds composed of chitosan as a framework containing low concentrations of hyaluronic acid to mimic cartilage ECM composition. The application of HA as a component of the cartilage scaffold biomaterial, could be a reasonable approach for enhancing chondrogenesis. We hypothesized that HA could provide superior effects on the formation, structural and biological properties of chitosan scaffolds, by providing a suitable microenvironment where chondrocytes may produce a cartilage-specific matrix for cartilage regeneration. To test this hypothesis, hyaluronic acid was added to chitosan solution in a final polymer concentration of $2 \%(\mathrm{w} / \mathrm{v})$ to prepare 3D scaffolds by freeze-drying method [19]. Using this method, porous scaffolds are easily prepared with controllable pore size, uniform pore distribution and functional features. Four types of scaffolds were obtained containing either no HA (control, $\mathrm{CHT}), 1 \%$ (CHT/1HA), 5\% (CHT/5HA), and 10\% of HA (CHT/10HA). The physic-chemical properties and biological behavior of the developed scaffolds were evaluated to study the hyaluronic acid influence in the CHT scaffolds in different parameters, including pore size and geometry, mechanical properties, and cartilage ECM production.

\section{Materials and methods}

\subsection{Materials}

Chitosan medium molecular weight $\left(\mathrm{M}_{\mathrm{w}}\right.$ 190.000-310.000, 75-85\% deacetylation degree, viscosity 200-800 cps) and hyaluronic acid (\#81, Lot Dev 00453, Mw 1.8 million) were purchased from Sigma-Aldrich. Before being used, chitosan was purified by recrystallization. Chitosan was dissolved in $1 \%(\mathrm{w} / \mathrm{v})$ acetic acid solution and then filtered under vacuum through porous

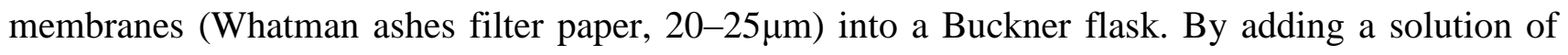
sodium hydroxide, the $\mathrm{pH}$ of the solution was adjusted to 8 , causing flocculation due to deprotonation and insolubility of the polymer at neutral $\mathrm{pH}$. The polymer solution was then 
neutralized until the $\mathrm{pH}$ was equal to that of distilled water. Samples were frozen at $-80{ }^{\circ} \mathrm{C}$ and lyophilized. Lysozyme from chicken egg white (lyophilized powder, 100000 U/mg, stored at $4^{\circ} \mathrm{C}$ ) and hyaluronidase from bovine tests (Type VIII, $300 \mathrm{U} / \mathrm{mg}$, stored at $-20^{\circ} \mathrm{C}$ ) were purchased from Sigma-Aldrich.

\subsection{Methods}

\subsubsection{Preparation of chitosan and hyaluronic acid scaffolds}

Chitosan and hyaluronic acid were first separately dissolved $(1 \% \mathrm{w} / \mathrm{v})$ overnight at room temperature in diluted acetic acid (1\% v/v) and subsequently mixed in different ratios (w/v) in a final polymer concentration of $2 \%(\mathrm{w} / \mathrm{v})$. In order to obtain a cylindrical shape, the polymeric solutions were placed into plastic tubes and frozen for 1 day at $-80^{\circ} \mathrm{C}$. The plastic tubes were then cut in small pieces to obtain a scaffold dimension of $5 \mathrm{~mm} \times \emptyset 6 \mathrm{~mm}$. After freeze-drying, the scaffolds were neutralized with a solution of $\mathrm{NaOH}(0.1 \mathrm{M})$ and then freeze-dried again. Four types of scaffolds were obtained, containing $0 \%$ (control), $1 \%, 5 \%$ or $10 \%$ of hyaluronic acid (CHT; CHT/1HA; CHT/5HA; and CHT/10HA, respectively).

\subsubsection{Physicochemical characterization}

\subsubsection{Morphology and pore size}

Morphology of CHT/HA scaffolds was characterized by scanning electron microscopy. The scaffolds were gold-coated using a sputter coater (Cressington) for 60 seconds at a current of $40 \mathrm{~mA}$. Cross-sectional morphologies were viewed using a Philips XL 30 ESEM-FEG operated at $10 \mathrm{kV}$ accelerating voltage. Pore size was measured using a submenu, consisting on a ruler tool, incorporated in the software of the SEM equipment. Once obtained overall cross-sectional images of the scaffolds, were selected several pores (more than 20). In each selected pore, the ruler tool 
measured the diameter of the pore by measuring the distance between two points. In each crosssectional image of the scaffolds, the average pore size was calculated.

\subsubsection{Fourier Transform Infrared spectroscopy imaging measurements}

FT-IR measurements were performed using a Perkin-Elmer Spectrum Spotlight 200 FTIR Microscope System in reflectance mode. The four scaffolds formulations and a sample of pure hyaluronic acid were analyzed without further modifications in the range of $720-1800 \mathrm{~cm}^{-1}$. The selected region for chitosan identification was $1650 \mathrm{~cm}^{-1}$ which corresponds to $\mathrm{C}=\mathrm{O}$ stretching of amide I [26]. The selected region for hyaluronic acid was $1045 \mathrm{~cm}^{-1}$ which corresponds to C-O-C bond stretching vibration of symmetric ester band [27, 28]. To obtain the chemical maps, a submenu incorporated in the software of the FT-IR equipment was used. Two ranges and three colors were selected. For chitosan, the range $1630-1670 \mathrm{~cm}^{-1}$ integrates the amide I characteristic peak and it is represented in green. For hyaluronic acid, the range $1025-1065 \mathrm{~cm}^{-1}$ integrates the ester characteristic peak and it is represented in red. The color yellow was selected to represent the presence of the two characteristic peaks in simultaneous. Spectra were collected in continuous scan mode for sample areas of $85 \times 85 \mu \mathrm{m}^{2}$ with a spectral resolution of $16 \mathrm{~cm}^{-1}$ by averaging $15 \mathrm{scans}$ for each spectrum.

\subsubsection{Mechanical properties}

Mechanical compression tests of the scaffolds were performed using an INSTRON 5543 (Instron Int. Ltd., USA) up to $60 \%$ of strain, at room temperature. The testing machine was equipped with a $1 \mathrm{kN}$ load cell and the loading rate was $2 \mathrm{~mm} / \mathrm{min}$. The compressive modulus was calculated in the initial linear section of the stress-strain curve, when the strain was lower than $10 \%$. The mechanical properties of the scaffolds were tested in both dry and wet state. In the wet state assay, scaffolds were immersed in PBS at $\mathrm{pH} 7.4$ for 24 hours, in a shaking water bath at $37^{\circ} \mathrm{C}$ to simulate in vivo conditions and for complete hydration. Compressive mechanical tests were performed in $n=6$ per scaffold formulation in both assays. 


\subsubsection{Swelling properties}

The water sorption capacity of the scaffolds was determined by swelling of freeze-dried scaffolds (with known weights) in phosphate buffered saline (PBS, Gibco) at $\mathrm{pH} 7.4$ for 3 days at $37^{\circ} \mathrm{C}$. The swollen scaffolds were removed at predetermined time intervals $(15 \mathrm{~min}, 30 \mathrm{~min}, 1 \mathrm{~h}, 2 \mathrm{~h}, 4 \mathrm{~h}, 6 \mathrm{~h}, 8 \mathrm{~h}$, 24h, 2 days, and 3 days) and immediately weighted with an analytical balance (Scaltec, Germany) after the removal of excess of water by lying the surfaces on a filter paper (Whatman Pergamyn Paper, 100x100 mm). The swelling ratio (SR) was calculated using the following equation (1):

$$
\mathrm{SR}=\left(\mathrm{W}_{\mathrm{w}}-\mathrm{W}_{\mathrm{d}}\right) / \mathrm{W}_{\mathrm{d}}
$$

Where $\mathrm{W}_{\mathrm{w}}$ and $\mathrm{W}_{\mathrm{d}}$ are the weights of the scaffolds at the swelling state and at the dry state, respectively.

\subsubsection{Enzymatic Degradation}

CHT/HA scaffolds were placed at pH 7.4 in PBS (control) or at pH 7.11 in an enzymatic solution containing $2 \mathrm{mg} / \mathrm{mL}$ of lysozyme [29] and $0.33 \mathrm{mg} / \mathrm{mL}$ of hyaluronidase [30], in a shaking water bath at $37^{\circ} \mathrm{C}$. The medium was replaced every third day. At predetermined time intervals ( 7 and 14 days) scaffolds were taken from the solutions and washed with distilled water three times to remove salts. The weight was measured after the scaffolds were immersed in $100 \%$ ethanol for 2 hours and dried for 1 day at room temperature. The percentage weight loss (\%WL) of scaffolds was calculated according to the following equation (2):

$$
\% \mathrm{WL}=\left(\left(\mathrm{W}_{\mathrm{i}}-\mathrm{W}_{\mathrm{f}}\right) / \mathrm{W}_{\mathrm{i}}\right) \times 100 \%
$$

Where, $\mathrm{W}_{\mathrm{i}}$ is the initial dry weight of scaffold and $\mathrm{W}_{\mathrm{f}}$ is the weight of the dry scaffold after incubation in the PBS or enzymatic solution. 


\subsubsection{Bovine articular chondrocyte culture}

Bovine articular chondrocytes were isolated from freshly collected cartilage from a calf knee through enzymatic digestion, under sterile conditions. Briefly, cartilage was minced in small pieces, which were incubated overnight in DMEM with $0.2 \%$ collagenase II (Worthington). Afterwards, cells were washed with PBS solution (Gibco) and ressuspended in chondrocyte proliferation medium containing DMEM high glucose (Invitrogen), FBS (10\%, Sigma-Aldrich), non-essential amino acids (0.1mM, Sigma-Aldrich), penicillin/streptomycin $(100 \mathrm{U} / 100 \mu \mathrm{g} / \mathrm{mL}$, Invitrogen), proline $(0.4 \mathrm{mM}$, Sigma-Aldrich), and Asap (0.2 mM, Invitrogen), Ultimately, cells were seeded in plastic tissue culture flasks, and incubated in a humidified atmosphere with $5 \% \quad \mathrm{CO}_{2}$ at $37^{\circ} \mathrm{C}$. Adherent chondrocytes were expanded and the medium was changed every third day, until the cells achieved $80 \%$ of confluence.

Prior to cell seeding, the scaffolds were sterilized with $70 \%(\mathrm{v} / \mathrm{v})$ ethanol for 2 hours, rinsed three times in distilled water, and then they were immersed in PBS for 2 days. The seeding was performed by injection of a cell suspension, on which the cell concentration was adjusted to $0.5 \times 10^{6}$ cells in $20 \mu \mathrm{L}$ of medium (per scaffold). After incubation for 4 hours at $37^{\circ} \mathrm{C}$ in a $5 \% \mathrm{CO}_{2}$ atmosphere incubator, chondrocyte proliferation medium or chondrocyte differentiation medium (DMEM, 2mM glutamax (Gibco), 0.2mM Asap (Invitrogen), 100 $\mathrm{gg} / \mathrm{mL}$ penicillin/streptomycin, 0.4mM proline (Sigma-Aldrich), 100 $\mu \mathrm{g} / \mathrm{mL}$ Sodium Pyruvate (Sigma-Aldrich), and 50mg/mL ITS+premix (BD biosciences). Immediately before use: $10 \mathrm{ng} / \mathrm{mL}$ TGF- $\beta 3$ (R\&D Systems) and $0.1 \mu \mathrm{M}$ dexamethasone (Sigma-Aldrich)) were added to the seeded scaffolds, according to the type of assay performed.

\subsubsection{Biological assays}

To analyze cell viability, proliferation and adhesion of CHT/HA scaffolds, articular bovine chondrocytes were seeded by injection at passage 3 in proliferation medium. Live/dead and MTT assays were performed at 1, 3, 7, 14, and 21 days, according to manufacturer's specifications, and 
scaffolds were further observed by scanning electron microscopy. To evaluate the chondrogenic phenotype maintenance, articular bovine chondrocytes were seeded by injection at passage 1 in differentiation medium. Safranin-O and Alcian Blue stainings, quantitative GAG and DNA assays, and SEM observation were performed. Chondrocyte medium was changed every third day to maintain an adequate supply of cell nutrients.

\subsubsection{Live/dead assay}

Scaffolds were deposited in a 48-well plate. To perform this assay, chondrocyte proliferation medium was aspirated from the wells and the seeded scaffolds were incubated with ethidium homodimer-1 $(6 \mu \mathrm{M})$ and calcein-AM (4 mM) (Invitrogen) for 30 minutes in the dark at $37^{\circ} \mathrm{C}$ in a $5 \% \mathrm{CO}_{2}$ atmosphere incubator. Scaffolds were immediately examined in an inverted fluorescent microscope (Nikon Eclipse E600) using a FITC/Texas Red Filter. The images were captured using a color camera (Nikon FDX-35) and the QCapture software. Calcein-AM is enzymatically converted, producing fluorescent living cells, since live cells have intracellular esterase activity. Ethidium homodimer-1 is only able to enter dead cells and after binding to nuclei acids producing a red fluorescent signal.

\subsubsection{MTT assay}

Scaffolds were deposited in a 48-well plate and incubated with $1 \mathrm{~mL}$ of chondrocytes proliferation medium and $20 \mu \mathrm{L}$ MTT solution ( $5 \mathrm{mg} / \mathrm{mL}$, Gibco) per well for 2 hours at $37^{\circ} \mathrm{C}$ in a $5 \% \mathrm{CO}_{2}$ atmosphere incubator. MTT is a pale yellow substrate, which is reduced by living cells to formazan, which stains dark purple. This process requires active mitochondria and is, thus, an accurate measure of the metabolic activity of cells in a culture. At the above referred time intervals, MTT solution was added to each well. During this period, viable cells could reduce the MTT formazan. Images were captured using a color camera (Nikon SMZ-10A) and the MATRIX Vison SRGB 32Bit software. 


\subsubsection{Scanning Electron Microscopy observation}

Chondrocytes adhesion on scaffolds was analyzed by SEM $(n=2)$. CHT/HA scaffolds were immersed in $10 \%(\mathrm{v} / \mathrm{v})$ formalin overnight at $4^{\circ} \mathrm{C}$. Specimens were then dehydrated using sequential ethanol series $(70 \%, 80 \%, 90 \%, 96 \%$, and $100 \%(\mathrm{v} / \mathrm{v}), 1$ hour in each, and critical point dried using a Balzers CPD 030 machine. The scaffolds were gold-sputtered as previously described for further observation by SEM operated at $10 \mathrm{kV}$ accelerating voltage.

\subsubsection{Histology}

Safranin-O and alcian blue stainings were used to analyze cartilage tissue formation. Scaffolds were washed with PBS and fixed overnight in $10 \%$ formalin, and then dehydrated using sequential ethanol series $(70 \%, 80 \%, 90 \%, 96 \%$, and $100 \%(\mathrm{v} / \mathrm{v}), 1$ hour in each). Once dehydrated, they were incubated in butanol overnight, and then in a solution containing butanol and paraffin (50:50) for 8 hours. Ultimately, the scaffolds were embedded in paraffin and $5 \mu \mathrm{m}$ thick sections were cut using a microtome. After deparaffinazing with xylene and rehydratation using a graded ethanol series (from $100 \%$ to $70 \%(\mathrm{v} / \mathrm{v}))$ the samples were stained. For the safranin-O staining, sections were counter stained with haematoxylin (Sigma-Aldrich) and fast green (Merk) to visualize cells and cell nuclei, respectively, and safranin-O (Sigma-Aldrich) for visualization of glycosaminoglycans in red. For alcian blue staining, sections were stained with alcian blue solution ( $1 \%$ in acetic acid) for 30 minutes to visualize extracellular GAGs in blue. After washing steps, the samples were counterstained with nuclear fast red for 5 minutes. Slides were assembled with resinous medium and mounted slides were examined under a light microscope (Nikon Eclipse E600). Representative images were captured using a digital camera (Nikon FDX-35) and QCapture software. Each assay was performed at either $1,14,21$, and 35 days of culture in duplicate ( $\mathrm{n}=2$ per scaffold formulation).

\subsubsection{Quantitative GAG and DNA assays}

CHT/HA scaffolds were washed with PBS and frozen at $-80^{\circ} \mathrm{C}$ for quantitative analysis of GAG expression and cell number. Subsequently, they were digested with $1 \mathrm{mg} / \mathrm{mL}$ proteinase K (Sigma- 
Aldrich) in Tris/EDTA buffer (pH 7.6) containing $18.5 \mu \mathrm{g} / \mathrm{mL}$ iodoacetamide and $1 \mu \mathrm{g} / \mathrm{mL}$ pepstatin A (Sigma-Aldrich) for 20 hour at $56^{\circ} \mathrm{C}$. GAG content was spectrophotometrically determined with DMMB (Sigma-Aldrich) staining in PBE buffer (PBS containing $14.2 \mathrm{~g} / \mathrm{L} \mathrm{Na} \mathrm{HPO}_{4}$ and $3.72 \mathrm{~g} / \mathrm{L}$ $\mathrm{Na}_{2}$ EDTA, pH 6.5) with a monochromatic microplate reader (TECAN Safire 2, Austria) at an absorbance of $520 \mathrm{~nm}$. The standard curve for the GAG analysis was generated using chondroitin sulphate A (Sigma-Aldrich). Quantification of total DNA was determined with the CyQuant DNA kit, according to the manufacturer's description (Molecular Probes, Eugene, Oregon, USA), using a fluorescent plate reader (emission: $520 \mathrm{~nm}$; excitation: $480 \mathrm{~nm}$ ) (Perkin-Elmer, Victor 3, USA). The standard curve for DNA analysis was generated with $\lambda$ DNA provided with the CyQuant DNA kit. The assays were performed at 1, 14, 21, and 35 days of culture.

\subsubsection{Statistical analysis}

Each experiment was carried out in triplicate unless otherwise specified. All results are presented as mean \pm standard deviation (SD). Experimental data were analyzed using single-factor Analysis of Variance (ANOVA) technique to assess statistical significance of results. Statistical significance was set to $p$-value $\leq 0.05(*)$ or to $p$-value $\leq 0.01(* *)$.

\section{Results and discussion}

\subsection{Physicochemical characterization of chitosan-hyaluronic acid scaffolds}

\subsubsection{Scaffolds preparation and microstructure observation}

Concentrations of HA-based scaffolds are usually limited to $2 \% \mathrm{w} / \mathrm{v}$, or less, because higher concentrations are too viscous for adequate mixing [31]. The morphologies of the scaffolds were investigated based on different ratios between CHT and HA. In order to characterize the microstructure morphology of chitosan and hyaluronic acid scaffolds, cross-sectional SEM images were obtained (Correia.Fig1). CHT scaffolds showed a closed network pore configuration with 
sheet-like areas (arrow in Correia.Fig1 $\mathrm{C}_{0}$ ). In contrast, CHT/1HA and CHT/5HA scaffolds showed a more open network structure. These two formulations had high porosity and uniformly distributed pore structures. In CHT/10HA scaffolds, pore geometry was very irregular with closed or oversized collapsed pores (arrow in Correia.Fig1 $\mathrm{C}_{10}$ ). This influence on porosity and pore structure when HA was incorporated in scaffolds of polycationic polymers was also found by Ren et al. [13]. The differences between the pore architecture are at least partially related to the homogeneity of the polymeric solution; i.e. how well are the two polymers mixed and dispersed in the solution. Since chitosan and hyaluronic acid have an opposite charge, an ionic bond between the carboxyl groups of HA and the amino groups of chitosan is expected [15]. As the concentration of HA increased in the CHT/HA formulation, the solution become more opaque. The incorporation of HA up to a concentration of $5 \%$ in a CHT solution yielded a well dispersed colloidal suspension. CHT/5HA suspension was stable indicating the formation of sub-micrometer complexes. In contrast, higher concentrations of HA jeopardized efficient mixture of both polymers, resulting in white precipitates. These precipitates tended to aggregate and, consequently, after freeze-dried, resulted in a nonuniform pore geometry (Correia.Fig1 $\mathrm{C}_{10}$ ). Mao et al. [32] also studied chitosan and hyaluronic acid blends, and correlated the formation of white precipitates with the high density of carboxyl groups in hyaluronic acid and amino groups in chitosan.

Pore size increased with concentrations of hyaluronic acid in chitosan scaffolds (Correia.Table1). Fan et al. [31] reported the same influence of HA on scaffold pore size. CHT/10HA also exhibited the highest standard deviation in pore sizes due to the non-uniform pore geometry. The open pore network and a range in pore size between $\approx 77-97 \mu \mathrm{m}$, as observed in CHT/1HA and CHT/5HA scaffolds, rendered these scaffolds appropriate for cellular infiltration. Particularly, we hypothesize that articular bovine chondrocytes can be incorporated into the above mentioned scaffolds. 


\subsubsection{Fourier Transform Infrared spectroscopy imaging measurements}

FT-IR measurements (Correia.Fig2) confirmed the presence of chitosan and hyaluronic acid in all CHT/HA scaffolds. Characteristic peaks of both polymers (Correia.Fig2 (a)) were founded, namely a distinct band at $1650 \mathrm{~cm}^{-1}$ (amide I) and at $1580 \mathrm{~cm}^{-1}$ (amide II) [26]. The ester group (1045 $\mathrm{cm}^{-1}$ ), a HA characteristic peak, is the main difference between the two spectra. The referred characteristic peaks were also founded in all CHT/HA scaffolds spectra (Correia.Fig2 (b)). Particularly, CHT/10HA had a notable higher intensity in the ester peak, since is the formulation with higher amount of HA.

The homogeneity of the CHT/HA blends was investigated by FT-IR mapping (Correia.Fig3). As expected, chemical maps of CHT scaffolds (Correia.Fig3 (a)) and pure hyaluronic acid (Correia.Fig3 (b)) only showed the selected color for the pure materials (green and red, respectively). As showed in Correia.Fig3 (d), CHT/5HA scaffolds had an improved polymer mixture, in which the two polymers were well dispersed in the length scale analyzed (tens of microns). On the other hand, in CHT/10HA scaffolds the quality of the blend was comprised. There could be seen more green and red areas, which corresponds to chitosan and hyaluronic acid alone, respectively, and less yellow, which corresponds to the homogeneously blended biomaterials.

\subsubsection{Mechanical Properties}

The mechanical properties of the scaffolds in tissue engineering applications are of great importance due to the necessity of structural stability to withstand stresses incurred during in vitro culture and in vivo implantation [31].

Compressive mechanical tests were performed using acellular scaffolds in dry and wet state. The compressive modulus of the scaffolds is shown in Correia.Table1. All samples exhibited a spongelike behavior. For both assays, the addition of HA in chitosan networks reduced the mechanical strength of the scaffold, while it increased its flexibility. This behavior may essentially be due to the 
increase in pore size by increasing the HA concentration. It was interesting to notice that $\mathrm{CHT} / 1 \mathrm{HA}$ and CHT/5HA scaffolds had similar compressive modulus in dry and wet state, probably due to their similar pore network.

Beside to an increase in pore size, O'Brien et al. [33] reported a correlation between decreasing mechanical strength and non-uniform pore shape in HA-based scaffolds. This may explain the reason why CHT/10HA had a much lower compressive modulus.

In the dry state, the compressive modulus of CHT/HA scaffolds were lower but in the same order of magnitude when compared to the modulus of articular cartilage reported by Korhonen et al. [34]. The compressive modulus in wet state was much lower compared to the dry state due to hyaluronic acid's ability for high water uptake. Since chitosan and hyaluronic acid are two natural polymers, this drawback in terms of mechanical strength was expected. However, the principal aim of incorporating HA into CHT scaffolds was to mimic the native cartilage ECM. The compressive modulus may further improve by the deposition of an extracellular matrix by chondrocytes in CHT/HA scaffolds.

\subsubsection{Swelling Properties}

Diffusion and exchange of nutrients (e.g. oxygen) and waste throughout the entire scaffold are related to the swelling properties of the scaffolds. Both chitosan and hyaluronic acid have an abundant number of hydrophilic groups, such as hydroxyl, amino and carboxyl groups, which can promote the water uptake in the structure [25]. The swelling ability was evaluated by soaking the scaffolds in PBS at $37^{\circ} \mathrm{C}$ for 3 days (Correia.Fig4). The ratio between chitosan and hyaluronic acid significantly affected the scaffolds swelling properties. In the first 2 hours, all samples rapidly increased their weight. This rapidly weight increase continued until 8 hours. Then, the swelling ratio of all samples seemed to stabilize, and a slight increase could be observed with time. CHT scaffolds had the lowest values during the entire experiment, while CHT/10HA the highest. CHT/1HA and 
CHT/5HA had similar swelling. The swelling results indicated that HA incorporation can greatly improve hydrophilicity and wetting of chitosan scaffolds. Hence, scaffolds with higher content of HA showed higher values of swelling. This aspect may imply that the absorption and diffusion of solutes through the interior pores in CHT scaffolds is greatly improved by incorporation of low concentrations of HA.

\subsubsection{In vitro enzymatic degradation}

Scaffolds for tissue engineering are usually required to either degrade or be reabsorbed by the body after successful tissue regeneration. Chitosan/hyaluronic acid scaffolds were incubated in a solution with lysozyme and hyaluronidase, or in a solution with PBS (control), both at $37^{\circ} \mathrm{C}$ for 7 and 14 days, to evaluate the weight decrease in the biopolymers due to enzymatic degradation. The weight loss percentage of scaffolds as a function of incubation time is illustrated in Correia.Fig5.

To distinguish between enzymatic degradation and simple dissolution, we compared the weight loss of samples that had been placed in PBS (Correia.Fig5 (a)) to those that had been placed in PBS supplemented with lysozyme and hyaluronidase at 7 and 14 days (Correia.Fig5 (b)). According to Correia.Fig5 (b), the presence of HA rendered CHT scaffolds more susceptible to enzymatic degradation, which is most likely due to a higher porosity and better accessibility of cleavage sites by the enzymes. The hydrophilicity of HA also contributed to a higher degradation of CHT/HA scaffolds as it will enhance the interaction of the biomaterial with the enzymatic solution. After a high initial weight loss at day 7 , the degradation rate of the samples generally appeared to slow down at day 14 , which is most likely due to the gradual disappearance of hexasaccharide sequences susceptible for enzymatic degradation. The control experiment in PBS (Correia.Fig5 (a)), showed that practically none of the scaffolds degrade in PBS after 14 days. The degradation of chitosan has already been tested in several in vitro studies [35-38]. Most of these studies were, however, performed at low $\mathrm{pH}$ for optimal lysozyme activity. In our study the enzymatic degradation experiments were performed at higher $\mathrm{pH}$, which resembles better degradation of the scaffolds in 
physiological conditions. Hyaluronidase and lysozyme concentrations used in this study (0.33 $\mathrm{mg} / \mathrm{mL}$ and $2 \mathrm{mg} / \mathrm{mL}$, respectively) are not representative of their concentration in vivo. The largest single reservoir of hyaluronidase is the synovial fluid of diarthrodial joints $(0.5$ to $4 \mathrm{mg} / \mathrm{mL})$ [39]. Lysozyme commonly exists in various human body fluids and tissues, with concentrations ranging from 4 to $13 \mathrm{mg} / \mathrm{L}$ in serum [40] and from 450 to $1230 \mathrm{mg} / \mathrm{L}$ in tears [41].

\subsection{In vitro articular bovine chondrocyte culture}

\subsubsection{Cell viability, proliferation, and adhesion studies on CHT/HA scaffolds}

In a live-dead assay, all materials exhibited very good biocompatibility with hardly any detectable cell death (Correia.Fig6). Furthermore, cells were metabolically active (Correia.Fig7) and well spread throughout the scaffolds in all formulations. The presence of increasing concentrations of HA did not influence cell loading of CHT scaffolds. This behavior is essentially due to the low capacity for cell attachment of chitosan.

The cell morphology and proliferation on CHT/HA scaffolds was further studied by scanning electron microscopy (Correia.Fig8). In all scaffolds, chondrocytes were primarily localized in the superficial area at day 1 and 3, and displayed a spherical morphology (cell size diameter $\approx 10 \mu \mathrm{m}$ ). At day 7, a limited increase in cell number was observed but cells did not penetrate into the scaffolds. At days 14 and 21, chondrocytes seeded in CHT/5HA scaffolds significantly proliferated into the inner areas of the scaffolds. In all scaffolds, even after 21 days of culture, the cells continued to display a normal spherical morphology, as observed in native cartilage.

\subsubsection{Maintenance of chondrogenic phenotype}

The round shape of chondrocytes is an indicator of phenotype retention and is essential for matrix formation [42]. The newly formed matrix was stained with safranin-O (Correia.Fig9) and alcian blue (Correia.Fig10) stainings, which showed glycosaminoglycans secretion. Since HA is a non-sulphated glycosaminoglycan, it stains blue in alcian blue staining. Low amounts of HA in the scaffold can be 
easily distinguished from newly deposited ECM by the chondrocytes by comparing alcian blue staining at 1 (Correia.Fig10 $\left.\mathrm{A}_{1}-\mathrm{A}_{35}\right)$ with staining at later time intervals. At day 1 , chondrocytes did not attached to the walls of CHT scaffolds, whereas in CHT/HA scaffolds cells attached to walls forming small aggregates. At day 14, in CHT/5HA scaffolds (Correia.Fig9 $\mathrm{C}_{14}$ and Correia.Fig10 $\mathrm{C}_{14}$ ) it was interesting to notice that most chondrocytes agglomerated to form very large aggregates adherent to the scaffolds. The aggregates were located on the superficial area. Hardly any penetration of cells in the scaffolds was observed. These events were also reported by Zhao et al. [43]. CHT/1HA and CHT/5HA showed an enhanced cell-material interactions and ECM production, with enhanced glycosaminoglycans production (Correia.Fig9 and Correia.Fig10). At day 35, CHT/5HA scaffolds showed better cell dispersion, and higher ECM production and GAG deposition compared to the other formulations. Chondrocytes seeded in CHT scaffolds, even at day 35, remained in small aggregates (Correia.Fig9 $\mathrm{A}_{35}$ and Correia.Fig10 $\mathrm{A}_{35}$ ).

Enhanced cartilage tissue formation can be also qualitatively detected by SEM analysis (Correia.Fig11). At day 1, chondrocytes were in aggregates in all specimens, but at day 14 they were better spread and attached. At days 14 and 21, improved chondrocyte dispersion could be noticed in CHT/1HA and CHT/5HA scaffolds. In all specimens lacunae formation was seen in the matrix surrounding the chondrocytes. The morphology of these lacunas shows similarities to natural cartilage.

\subsubsection{Chondrogenic activity evaluation}

It is known that when chondrocytes maintain their natural spherical shape they produce more GAGs and higher collagen type II versus collagen type I ratio [44-46]. Cell proliferation and ECM formation were quantified by DNA and GAG assays, respectively. In GAG quantification assay (Correia.Fig12 (a)) the incorporation of HA seemed to initiate an earlier glycosaminoglycans deposition, particularly at day 14 for CHT/1HA and CHT/5HA scaffolds. Results showed that the 
incorporation of HA seemed to favor GAG deposition, since at day 35 all the scaffolds containing HA had more GAG deposition compared to CHT scaffolds. For DNA quantification assay (Correia.Fig12 (b)), CHT/5HA had the highest amount of DNA at day 14. However, at day 35 CHT/1HA scaffolds significantly supported a higher amount of cells compared to other formulations. A higher value of GAG/DNA ratio indicates a higher degree of differentiation of the cells [47]. For GAG/DNA ratio (Correia.Fig12 (c)), it could be seen that at day 35, scaffolds with higher amount of hyaluronic acid (CHT/5HA and CHT/10HA) induced a higher ratio. Although CHT/1HA had the highest amount of cells in DNA quantification, CHT/5HA had the highest GAG versus DNA ratio. This may imply that CHT/5HA scaffolds are the formulation which most favors cartilage ECM production, rendering them attractive for cartilage TE.

\subsection{Physicochemical effects of CHT/HA scaffolds on cartilage regeneration}

The key challenge for biomedical researchers is how to design and control material properties in order to achieve a specific biological response [48]. It is well established that physicochemical properties of materials can regulate biological responses, such as differentiation of stem cells [49], proliferation of fibroblasts [50], gene delivery [51], and cell death [52].

CHT/1HA and CHT/5HA scaffolds exhibited a uniform pore network with high porosity (Correia.Fig1) and a homogeneous polymer dispersion (Correia.Fig3), rendering them to be appropriate for bovine chondrocyte culture. The pore configuration allowed cellular infiltration into the inner pores of the scaffolds (Correia.Fig8). On the other hand, CHT and CHT/10HA scaffolds had a very irregular pore network configuration with closed pores. Consequently, in these scaffolds the adhesion and proliferation of chondrocytes was jeopardized compared to the other formulations. The scaffolds high water uptake ability (Correia.Fig4) allowed the chondrocyte medium to reach the interior pores of the scaffolds. Consequently, diffusion and exchange of nutrients and waste 
throughout the scaffolds was ensured, allowing cells to proliferate and be metabolically active (Correia.Fig6 and Correia.Fig7).

Besides appropriate pore network and water uptake ability, CHT/1HA and, especially, CHT/5HA had an improved glycosaminoglycan dispersion and deposition (Correia.Fig9 and Correia.Fig10). Additionally, the two referred formulations had similar compressive modulus. Hence, physical and chemical factors seem to simultaneously influence the biological outcome. Cartilage regeneration seemed to be favored simultaneously by chemical aspects, i.e. intermediate amounts of HA (1 and $5 \%$ ), and also by physical aspects, i.e. the referred scaffolds formulations have also similar compressive modulus and a uniform pore network configuration. Therefore, in this case scenario it is not possible to distinguish case by case the detailed mechanisms of how physical properties affect the biological performance of the CHT/HA scaffolds. Despite of this unclear contribution of each parameter, the results obtained in our study are not compromised.

\section{Conclusions}

The incorporation of hyaluronic acid up to a concentration of $5 \%$ in chitosan scaffolds improved the physicochemical properties and biological properties of CHT scaffolds. It enhanced pore network configuration, increased pore size, swelling ratio and degradation rate compared to pure $\mathrm{CHT}$ scaffolds. Higher concentrations of HA resulted in heterogeneous blends with irregular and collapsed pore networks, particularly CHT/5HA scaffolds favored chondrocyte adhesion, cell proliferation, and cartilage matrix production compared to pure CHT scaffolds and other CHT/HA blends.

The biological outcome of CHT/HA scaffolds seems to be influenced by physicochemical factors, such as polymer dispersion, pore network configuration, pore size, water uptake ability, and mechanical strength. However, other studies are required to elucidate case by case the dependence of biological response to physical properties, and to categorize the relative weight of different physical and chemical factors. 
Our results suggest that the freeze-dried scaffolds of CHT and HA could have potential use in the regeneration of cartilaginous lesions caused by various joint diseases, including osteoarthritis and rheumatoid arthritis.

\section{Author Disclosure Statement}

No competing financial interests exist.

\section{References}

[1] Wu, S.C., Chang, J.K., Wang, C.K., Wang, C.J., and Ho, M.L. Enhancement of chondrogenesis of human adipose derived stem cells in a hyaluronan-enriched microenvironment. Biomaterials 31, $631,2010$.

[2] Bobic, V., and Noble, J. Articular cartilage, to repair or not to repair. J Bone Joint Surg Br 82, $165,2000$.

[3] Temenoff, J.S., and Mikos, A.G. Review: tissue engineering for regeneration of articular cartilage. Biomaterials 21, 431, 2000.

[4] Gobbi, A., Nunag, P., and Malinowski, K. Treatment of full thickness chondral lesions of the knee with microfracture in a group of athletes. Knee Surg Sports Traumatol Arthrosc 13, 213, 2005. [5] Lee, J., Lee, J.Y., Lee, E., and Son, Y. Newborn calf serum retards loss of the chondrocytic phenotype during in vitro cell expansion. J Tissue Eng Regen Med 6, 229, 2009.

[6] Lin, Y.C., Tan, F.J., Marra, K.G., Jan, S.S., and Liu, D.C. Synthesis and characterization of collagen/hyaluronan/chitosan composite sponges for potential biomedical applications. Acta Biomater 5, 2591, 2009.

[7] Mano, J.F., and Reis, R.L. Osteochondral defects: present situation and tissue engineering approaches. J Tissue Eng Regen Med 1, 261, 2007. 
[8] Chen, G., Ushida, T., and Tateishi, T. Scaffold design for tissue engineering. Macromol Biosci 2, 67, 2002.

[9] Goldring, M.B., Tsuchimochi, K., and Ijiri, K. The control of chondrogenesis. J Cell Biochem 97, 33, 2006.

[10] Yoo, H.S., Lee, E.A., Yoon, J.J., and Park, T.G. Hyaluronic acid modified biodegradable scaffolds for cartilage tissue engineering. Biomaterials 26, 1925, 2005.

[11] Kim, I.Y., Seo, S.J., Moon, H.S., Yoo, M.K., Park, I.Y., Kim, B.C., and Cho, C.S.

Chitosan and its derivatives for tissue engineering applications. Biotechnol Adv 26, 1, 2008.

[12] Ghosh, P., and Guidolin, D. Intra-articular Hyaluronan Therapy in Osteoarthritis. Semin Arthritis Rheum 32, 10, 2002.

[13] Ren, Y.J., Zhou, Z.Y., Liu, B.F., Xu, Q.Y., and Cui, F.Z. Preparation and characterization of fibroin/hyaluronic acid composite scaffold. Int J Biol Macromol 44, 372, 2009.

[14] Tian, W.M., Hou, S.P., Ma, J., Zhang, C.L., Xu, Q.Y., and Lee, I.S. Hyaluronic acid-poly-Dlysine-based three-dimensional hydrogel for traumatic brain injury. Tissue Eng 11, 513, 2005.

[15] Oyarzun-Ampuero, F.A., Brea, J., Loza, M.I., Torres, D., and Alonso, M.J. Chitosan-hyaluronic acid nanoparticles loaded with heparin for the treatment of asthma. Int J Pharm 381, 122, 2009.

[16] Tan, H., Wu, J., Lao, L., and Gao, C. Gelatin/chitosan/hyaluronan scaffold integrated with PLGA microspheres for cartilage tissue engineering. Acta Biomater 5, 328, 2009.

[17] Martino, A.D., Sittinger, M., and Risbud, M.V. Chitosan: a versatile biopolymer for orthopaedic tissue-engineering. Biomaterials 26, 5983, 2005.

[18] Kim, S.E., Park, J.H., Cho, Y.W., Chung, H., Jeong, S.Y., Lee, E.B., and Kwon, I.C. Porous chitosan scaffold containing microspheres loaded with transforming growth factor- $\beta 1$ : Implications for cartilage tissue engineering. J Control Release 91, 365, 2003.

[19] Oliveira, J.M., Rodrigues, M.T., Silva, S.S., Malafaya, P.B., Gomes, M.E., Viegas, C.A., Dias, I.R., Azevedo, J.T., Mano, J.F., and Reis, R.L. Novel hydroxyapatite/chitosan bilayered scaffold for 
osteochondral tissue-engineering applications: Scaffold design and its performance when seeded with goat bone marrow stromal cells. Biomaterials 27, 6123, 2006.

[20] Nge, T.T., Nogi, M., Yano, H., and Sugiyama, J. Microstructure and mechanical properties of bacterial cellulose/chitosan porous scaffold. Cellulose 17, 349, 2010.

[21] Tan, H., Chu, C.R., Payne, K.A., and Marra, K.G. Injectable in situ forming biodegradable chitosan-hyaluronic acid based hydrogels for cartilage tissue engineering. Biomaterials 30, 2499, 2009.

[22] Yamane, S., Iwasaki, N., Majima, T., Funakoshi, T., Masuko, T., Harada, K., Minami, A., Monde, K., and Nishimura, S.I. Feasibility of chitosan-based hyaluronic acid hybrid biomaterial for a novel scaffold in cartilage tissue engineering. Biomaterials 26, 611, 2005.

[23] Yamane, S., Iwasaki, N., Kasahara, Y., Harada, K., Majima, T., Monde, K., Nishimura, S.I., and Minami, A. Effect of pore size on in vitro cartilage formation using chitosan-based hyaluronic acid hybrid polymer fibers. J Biomed Mater Res A 81A, 587, 2006.

[24] Hsu, S.H., Whu, S.W., Hsieh, S.C., Tsai, C.L., Chen, D.C., and Tan, T.S. Evaluation of chitosan-alginate-hyaluronate complexes modified by an RGD-containing protein as tissue engineering scaffolds for cartilage regeneration. Artif Organs 28, 693, 2004.

[25] Chen, J.P., and Cheng, T.H. Preparation and evaluation of thermo-reversible copolymer hydrogels containing chitosan and hyaluronic acid as injectable cell carriers. Polymer 50, 107, 2009. [26] Chung, T.W., Yang, J., Akaike, T., Cho, K.Y., Nah, J.W., Kim, S. II, and Cho, C.S. Preparation of alginate/galactosylated chitosan scaffold for hepatocyte attachment. Biomaterials 23, 2827, 2002. [27] Ji, Y., Ghosh, K., Shu, X.Z., Li, B., Sokolov, J.C., Prestwic, G.D., Clark, R.A.F, and Rafailovich, M.H. Electrospun three-dimensional hyaluronic acid nanofibrous scaffolds. Biomaterials 27, 3782, 2006. 
[28] Antunes, J.C., Oliveira, J.M., Reis, R.L., Soria, J.M., Goméz-Ribelles, J.L., and Mano, J.F. Novel poly (L-lactic acid)/hyaluronic acid macroporous hybrid scaffolds: Characterization and assessment of cytotoxicity. J Biomed Mater Res A, 2010 (in press).

[29] Greenwald, R.A., Josephson, A.S., Diamond, H.S., and Tsang, A. Human Cartilage Lysozyme. J Clin Invest 51, 2264, 1972.

[30] Jin, R., Moreira-Teixeira, L.S., Krouwels, A., Dijkstra, P.J., van Blitterswijk, C.A., Karperien, M., and Feijen, J. Synthesis and characterization of hyaluronic acid-peg hydrogels via Michael addition: An injectable biomaterial for cartilage repair. Acta Biomater 6, 1968, 2010.

[31] Fan, J., Shang, Y., Yuan, Y., and Yang, J. Preparation and characterization of chitosan/galactosylated hyaluronic acid scaffolds for primary hepatocytes culture. J Mater Sci Mater Med 21, 319, 2010.

[32] Mao, J.S., Liu, H.F., Yin, Y.J., and Yao, K.D. The properties of chitosan-gelatin membranes and scaffolds modified with hyaluronic acid by different methods. Biomaterials 24, 1621, 2003.

[33] O’Brien, F.J., Harley, B.A., Yannas, I.V., and Gibson, L. Influence of freezing rate on pore structure in freeze-dried collagen-GAG scaffolds. Biomaterials 25, 1077, 2004.

[34] Korhonen, R.K., Laasanen, M.S., Töyräs, J., Rieppo, J., Hirvonen, J., Helminen, H.J., and Jurvelin, J.S. Comparison of the equilibrium response of articular cartilage in unconfined compression, confined compression and indentation. J Biomech 35, 903, 2002.

[35] Pangburn, S.H., Trescony, P.V., and Heller, J. Lysozyme degradation of partially deacetylated chitin, its films and hydrogels. Biomaterials 3, 105, 1982.

[36] Tomihata, K., and Ikada, Y. In vitro and in vivo degradation of films of chitin and its deacetylated derivatives. Biomaterials 18, 567, 1997.

[37] Lee, K.Y., Ha, W.S., and Park, W.H. Blood compatibility and biodegradability of partially Nacylated chitosan derivatives. Biomaterials 16, 1211, 1995. 
[38] Hirano, S., Tsuchida, H., and Nagao, N. N-acetylation in chitosan and the rate of its enzymatic hydrolysis. Biomaterials 10, 574, 1989.

[39] Fraser, J.R.E., Laurent, T.C., and Laurent, U.B.G. Hyaluronan: Its nature, distribution, functions and turnover. J Intern Med 242, 27, 1997.

[40] Nordtveit, R.J., Värum, K.M., and Smidsrød, O. Degradation of partially N-acetylated chitosans with hen egg white and human lysozyme. Carbohydr Polym 29, 163, 1996.

[41] Telmel, A., Kazokoglu, H., and Taga, Y. Tear lysozyme levels in contact lens wearers. Ann Ophthalmol 23, 191, 1991.

[42] Von der Mark, K., Gauss, V., von der Mark, H., and Muller, P. Relationship between cell shape and type of collagen synthesized as chondrocytes lose their cartilage phenotype in culture. Nature 267, 531, 1977.

[43] Zhao, K., Deng, Y., Chen, J.C., and Chen, G.Q. Polyhydroxyalkanoate (PHA) scaffolds with good mechanical properties and biocompatibility. Biomaterials 24, 1041, 2003.

[44] Woodfield, T.B.F., Miot, S., Martin, I., van Blitterswijk, C.A., and Riesle, J. The regulation of expanded human nasal chondrocyte re-differentiation capacity by substrate composition and gas plasma surface modification. Biomaterials 27, 1043, 2006.

[45] Miot, S., Woodfield, T.B.F., Daniels, A.U., Suetterlin, R., Peterschmitt, I., Heberer, M., van Blitterswijk, C.A., Riesle, J., and Martin, I. Effects of scaffold composition and architecture on human nasal chondrocyte redifferentiation and cartilaginous matrix deposition. Biomaterials 26, $2479,2005$.

[46] Barry, J.J., Gidda, H.S., Scotchford, C.A., and Howdle, S.M. Porous methacrylate scaffolds: supercritical fluid fabrication and in vitro chondrocyte responses. Biomaterials $\mathbf{2 5}, 3559,2004$.

[47] Moroni, L., Schotel, R., Hamann, D., de Wijn, J.R., and van Blitterswijk, C.A. 3D fiberdeposited electrospun integrated scaffolds enhance cartilage tissue formation. Adv Funct Mater 18, 53, 2008. 
[48] Mitragotri, S., and Lahann, J. Physical approaches to biomaterial design. Nat Mater 8, 15, 2009.

[49] Graziano, A., Aquino, R. d', Angelis, M.G.C-De., Francesco, F., Giordano, A., Laino, G., Piattelli, A., Traini, T., Rosa, A., and Papaccio, G. Scaffold's surface geometry significantly affects human stem cell bone tissue engineering. J Cell Physiol 214, 166, 2008.

[50] Milner, K.R., and Siedlecki, C.A. Submicron poly(L-lactic acid) pillars affect fibroblast adhesion and proliferation. J Biomed Mater Res A 82, 80, 2007.

[51] Shen, H., Tan, J., and Saltzman, W.M. Surface-mediated gene transfer from nanocomposites of controlled texture. Nat Mater 3, 569, 2004.

[52] Chen, C.S., Mrksich, M., Huang, S., Whitesides, G.M., and Ingber, D.E. Geometric control of cell life and death. Science 276, 1425, 1997.

\section{Address correspondence to:}

João F. Mano

3B's Research Group - Biomaterials, Biodegradables and Biomimetics, AvePark, Zona Industrial da Gandra, S. Cláudio do Barco, 4806-909 Caldas das Taipas, Guimarães, Portugal.

TEL.:+351253510904

Fax: +351253510909

E-mail address: jmano@dep.uminho.pt 


\begin{tabular}{|c|c|c|c|c|c|}
\hline \multicolumn{6}{|c|}{ Correia.Table1 } \\
\hline Sample code & $\begin{array}{c}\text { Chitosan } \\
\text { (\% wt) }\end{array}$ & $\begin{array}{l}\text { Hyaluronic } \\
\text { acid } \\
(\% \mathbf{w t})\end{array}$ & $\begin{array}{c}\text { Pore size } \\
(\mu \mathrm{m})\end{array}$ & $\begin{array}{l}\text { Compressive modulus } \\
\text { in dry state } \\
\text { (kPa) }\end{array}$ & $\begin{array}{c}\text { Compressive modulus } \\
\text { in wet state } \\
\text { (kPa) }\end{array}$ \\
\hline CHT & 100 & 0 & $55.80 \pm 10.04$ & $291.03 \pm 82.73$ & $2.84 \pm 0.41$ \\
\hline $\mathrm{CHT} / 1 \mathrm{HA}$ & 99 & 1 & $77.40 \pm 15.01$ & $144.33 \pm 28.32$ & $2.43 \pm 0.07$ \\
\hline $\mathrm{CHT} / 5 \mathrm{HA}$ & 95 & 5 & $97.43 \pm 6.56$ & $144.00 \pm 25.68$ & $2.30 \pm 0.06$ \\
\hline $\mathrm{CHT} / 10 \mathrm{HA}$ & 90 & 10 & $148.73 \pm 99.24$ & $40.73 \pm 18.31$ & $1.21 \pm 0.47$ \\
\hline
\end{tabular}

\section{New legends of figures}

Correia.Fig1 - SEM micrographs for cross-section (C) of the chitosan and hyaluronic acid scaffolds prepared, using different ratios of chitosan and hyaluronic acid $(n=3)$. The subscripts indicate the percentage of hyaluronic acid $(0,1,5$, and $10 \%)$. Original magnification is x100 and the scale bar represents $200 \mu \mathrm{m}$.

Correia.Fig2 - FT-IR spectra of (a) CHT scaffolds (solid green line) and pure hyaluronic acid (dashed red line) and of (b) CHT/1HA (solid green line), CHT/5HA (dashed yellow line) and CHT/10HA (dotted red line) scaffolds. The colored bands, $1670 \mathrm{~cm}^{-1}$ (yellow band) and $1045 \mathrm{~cm}^{-1}$ (red band), indicate the selected regions for the integration procedure used to obtain the images of Correia.Fig3.

Correia.Fig3 - Chemical maps obtained by FT-IR microscopy of the cross-sections of the scaffolds and of pure hyaluronic acid: (a) CHT, (b) HA, (c) CHT/1HA, (d) CHT/5HA and (e) CHT/10HA. Green indicates the presence of chitosan and red the presence of hyaluronic acid. The inset images individualize the presence of the pure polymers in the blends. The inset images next to Fig.3 (a) and (b) represent the images control for hyaluronic acid and chitosan, respectively. 
Correia.Fig4 - Swelling ratio of chitosan and hyaluronic acid scaffolds in $\mathrm{PBS}$ solution at $37^{\circ} \mathrm{C}$ for 3 days. Values are reported as mean \pm standard deviation $(\mathrm{SD})(\mathrm{n}=3)$.

Correia.Fig5 - Weight loss percentage of CHT/HA scaffolds as a function of incubation time (7 and 14 days) at $37^{\circ} \mathrm{C}$. Scaffolds were embedded in: (a) PBS solution or (b) enzymatic solution containing both lysozyme and hyaluronidase. Values are reported as mean $\pm \operatorname{SD}(n=3)$.

Correia.Fig6 - Live-dead assay results of chondrocytes at passage 3 in proliferation medium seeded on CHT/HA scaffolds at day $1,7,14$, and 21 . Live cells were stained in green by calcein and dead cells were stained red by ethidium $(n=3)$. The subscripts indicate the time period. The scale bar is $200 \mu \mathrm{m}$.

Correia.Fig7 - MTT assay results of chondrocytes at passage 3 in proliferation medium seeded on CHT/HA scaffolds at day 1, 7, 14, and $21(\mathrm{n}=3)$. Metabolic active cells were stained in dark purple. The subscripts indicate the time period. Original magnification is $x 7.5$. The scale bar is $3 \mathrm{~cm}$.

Correia.Fig8 - SEM micrographs $(10 \mathrm{kV})$ of CHT/HA scaffolds seeded with articular bovine chondrocytes at passage 3 in proliferation medium $(n=2)$. Original magnification is $x 500$. The scale bar is $50 \mu \mathrm{m}$. Arrows point to chondrocytes and/or cartilage deposition and stars to scaffold material.

Correia.Fig9 - Histological cross-sections show glycosaminoglycans deposition (stained red) in CHT/HA scaffolds by safranin-O staining at 1, 14, 21, and 35 days of chondrocyte culture in differentiation medium $(\mathrm{n}=2)$. Subscripts indicate time intervals. The scale bar is $100 \mu \mathrm{m}$.

Correia.Fig10 - Histological cross-sections show glycosaminoglycans deposition (stained blue) in CHT/HA scaffolds by alcian blue staining at $1,14,21$, and 35 days of chondrocyte culture in differentiation medium $(n=2)$. Subscripts indicate time intervals. The scale bar is $100 \mu \mathrm{m}$. 
Correia.Fig11 - SEM micrographs $(10 \mathrm{kV})$ of CHT/HA scaffolds seeded with articular bovine chondrocytes at passage 1 in differentiation medium $(n=2)$. Original magnification is $x 500$. The scale bar is $50 \mu \mathrm{m}$. Arrows point to chondrocytes and/or cartilage deposition and stars to scaffold material.

Correia.Fig12 - GAG and DNA assays on CHT/HA scaffolds at 1, 14, 21, and 35 days of culture: (a) GAGs assay, (b) DNA assay, (c) GAGs per DNA ratio. Values are reported as mean \pm standard deviation $(n=3) .(*)$ shows significant differences for $\mathrm{p} \leq 0.05$ and $(* *)$ for $\mathrm{p} \leq 0.01$.

\section{Legends of Tables}

Correia.Table1 - Pore size $(\mu \mathrm{m})$ and compressive modulus $(\mathrm{kPa})$ of the CHT/HA scaffolds prepared with different amounts of HA in dry and wet state. Values are reported as mean \pm SD. 


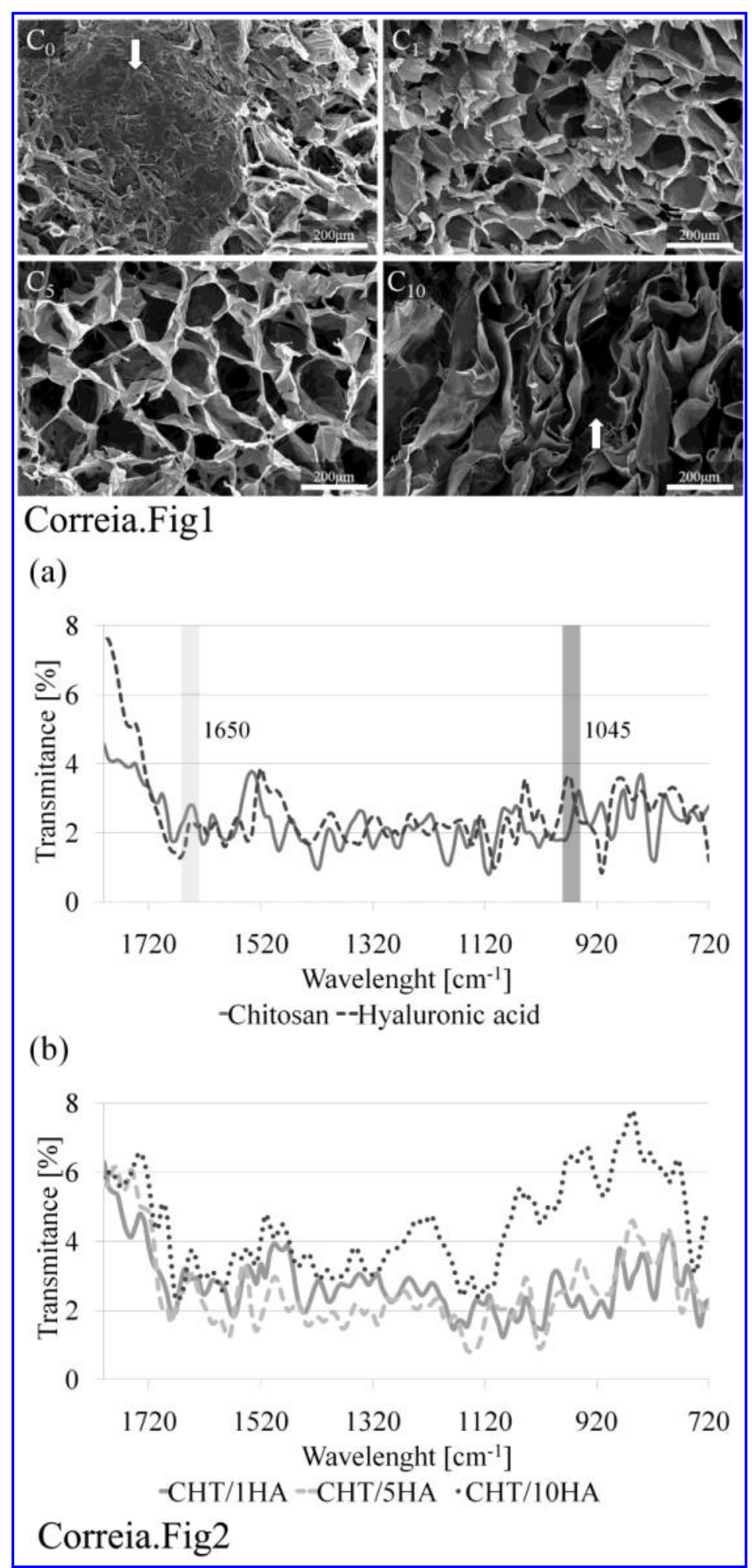


Page 32 of 37

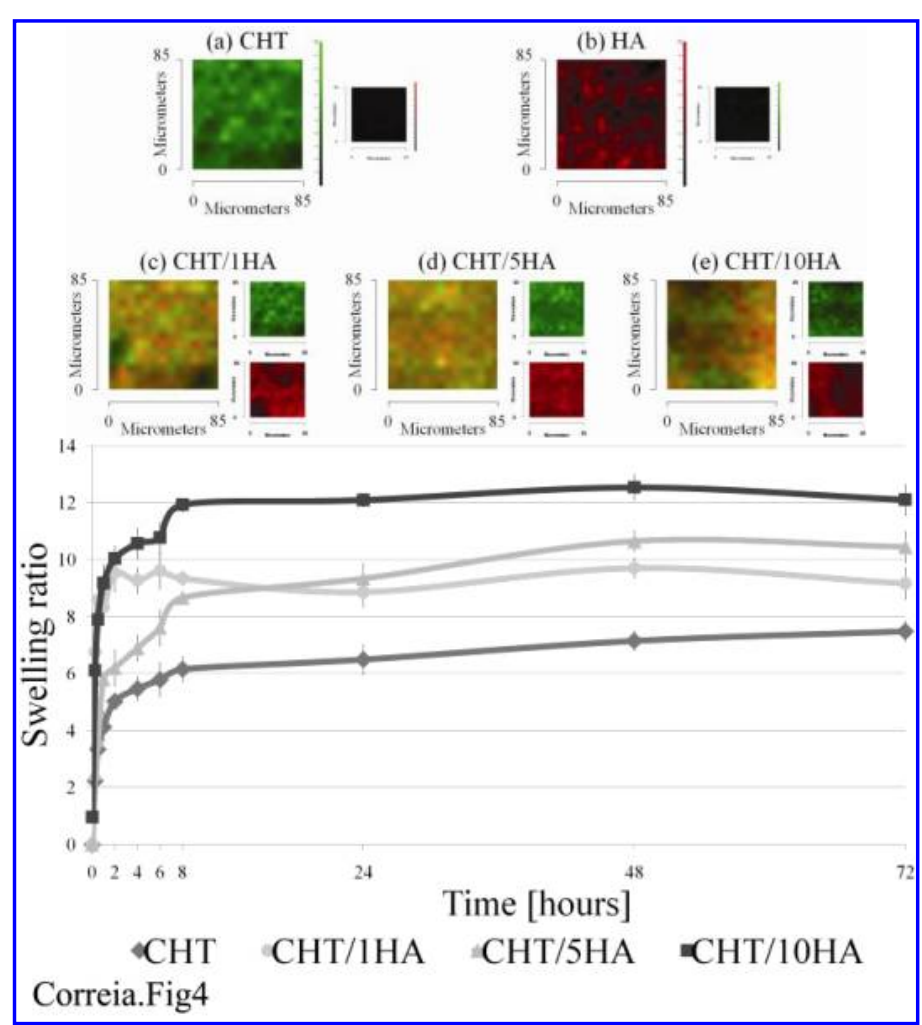

Correia.Fig4 
Page 33 of 37

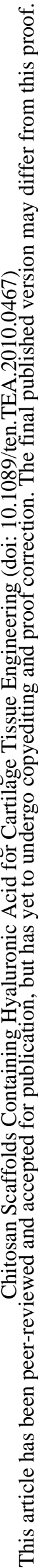

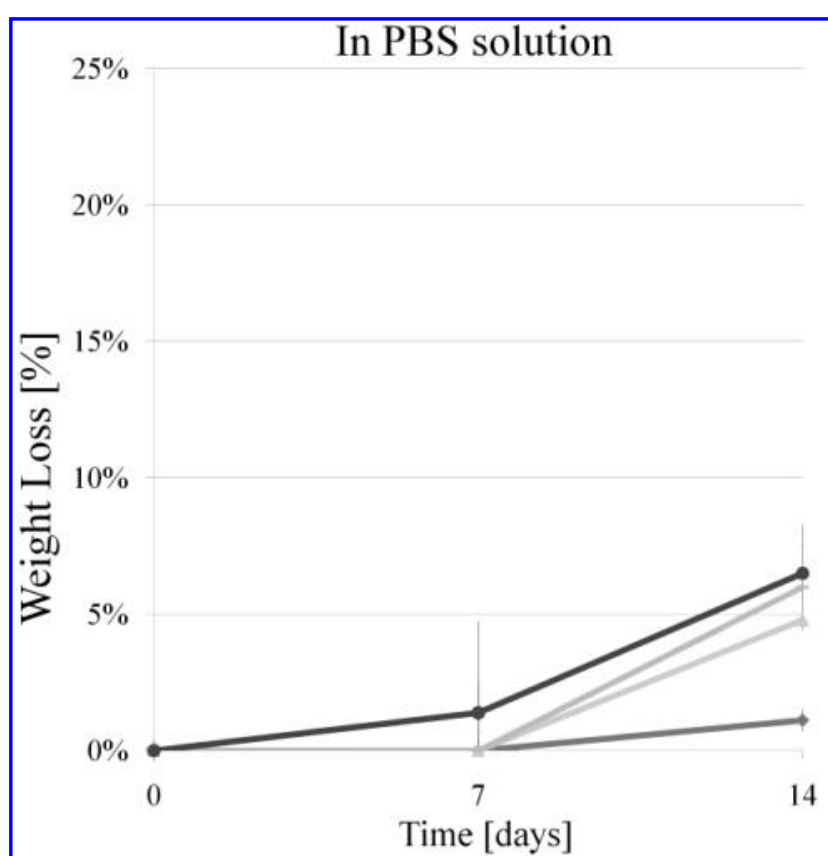

•CHT CHT/1HA CHT/5HA ${ }^{\mathrm{C}} \mathrm{HT} / 10 \mathrm{HA}$

(a)

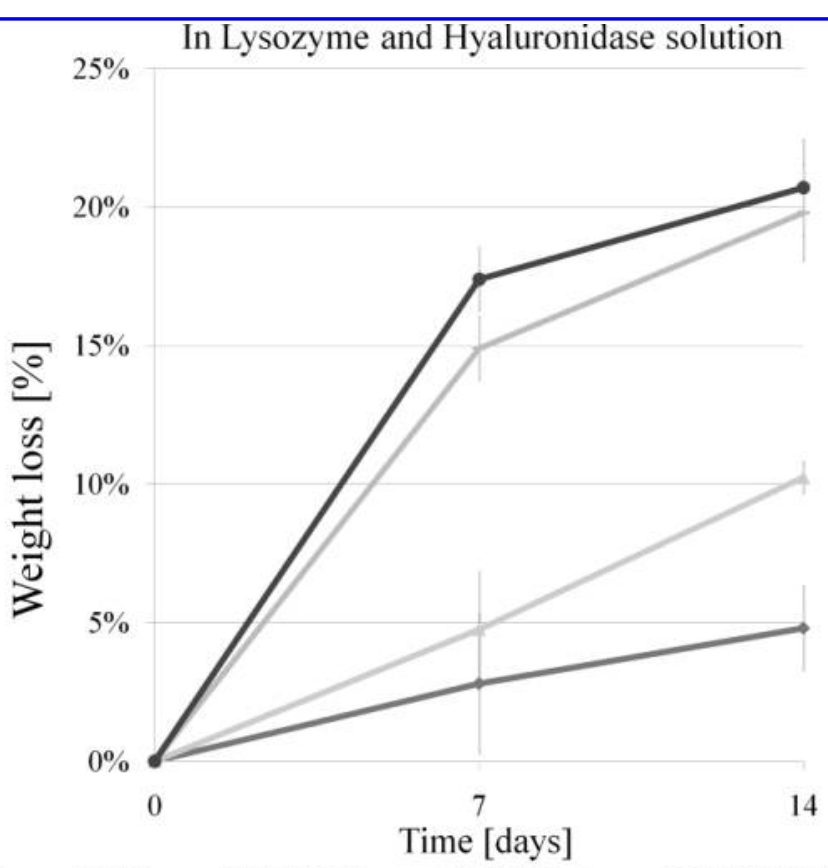

4

$\mathrm{CHT} / 5 \mathrm{HA} \quad{ }^{\mathrm{C}} \mathrm{HT} / 10 \mathrm{HA}$

(b)

Correia.Fig5

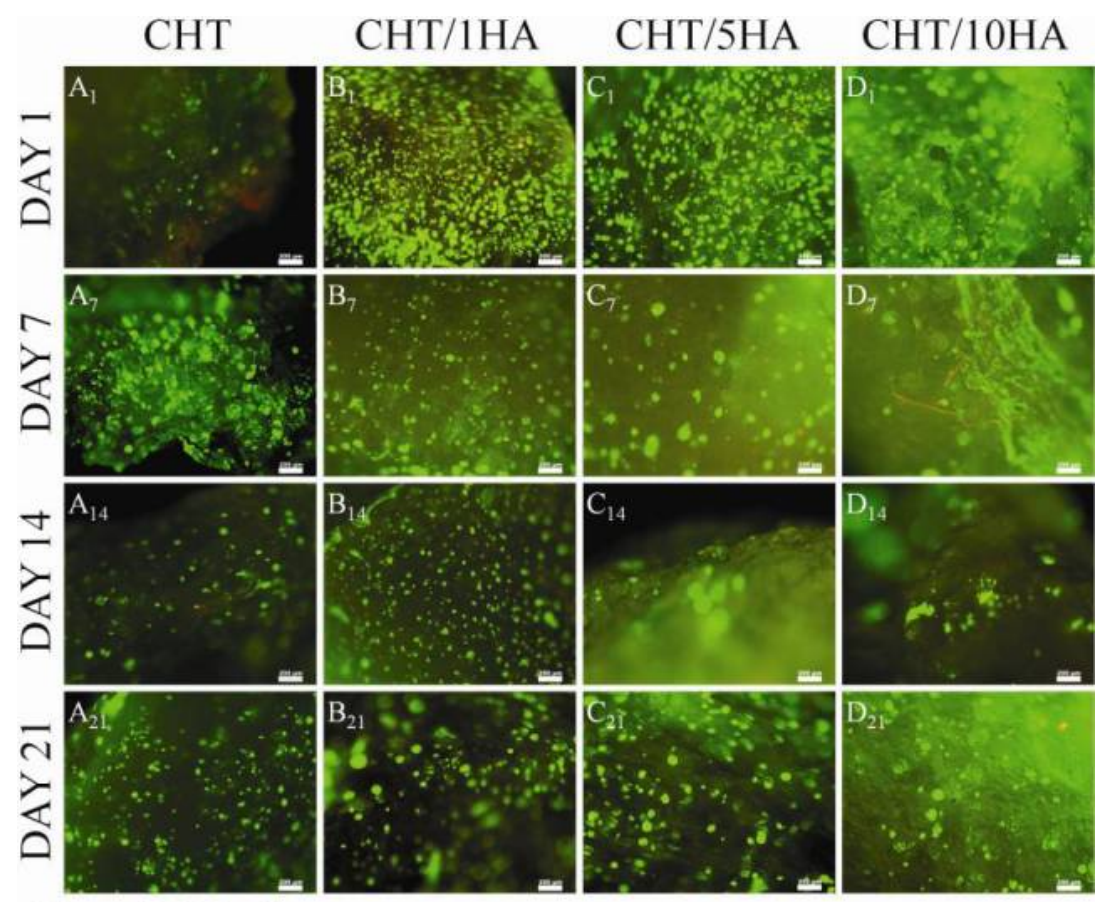

Correia.Fig6 


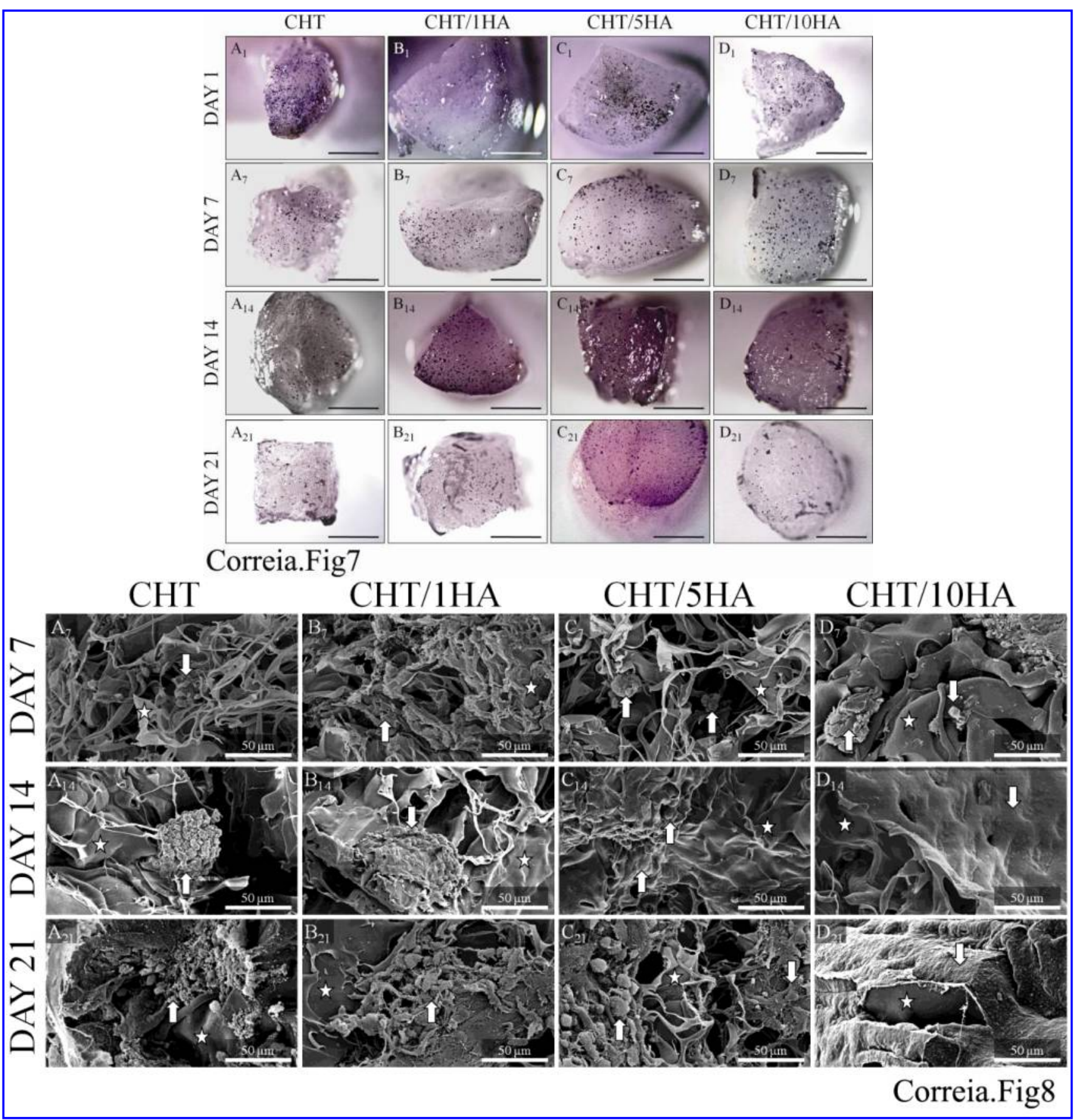

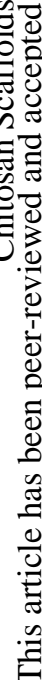

Correia.Fig8 


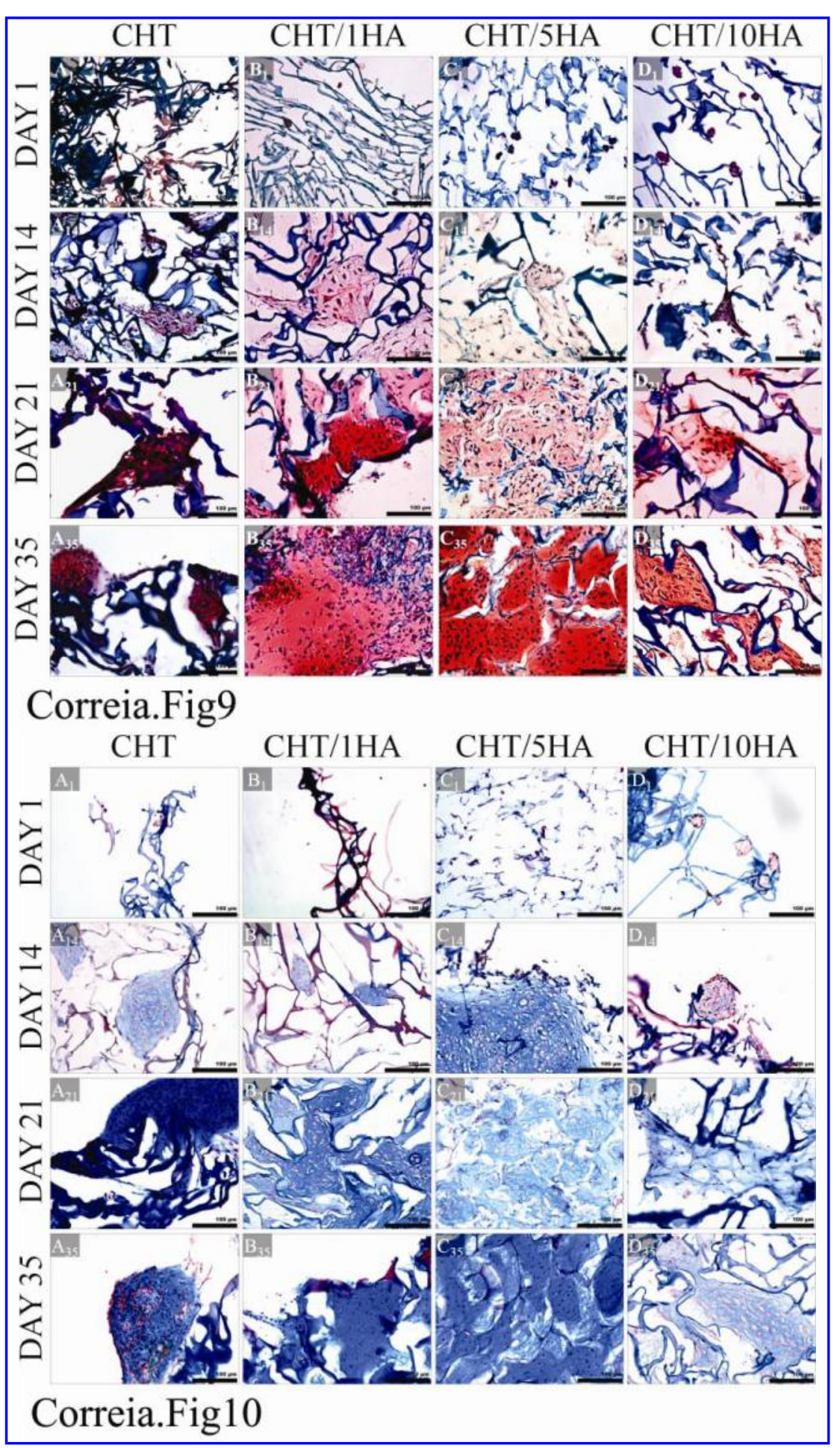


Page 36 of 37

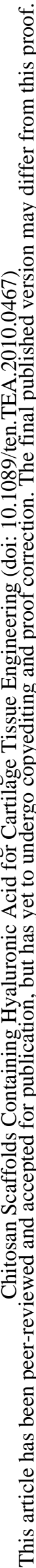

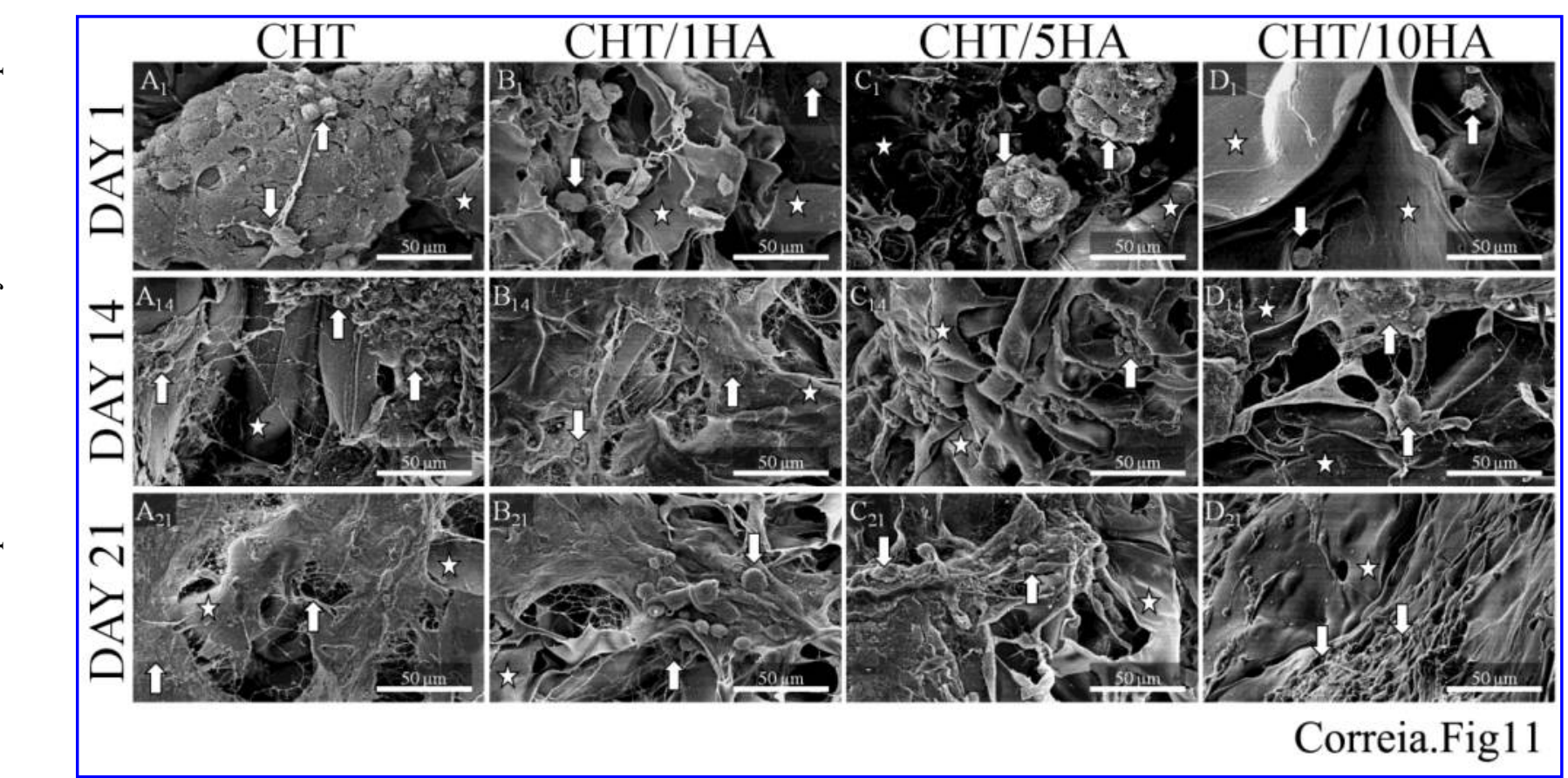

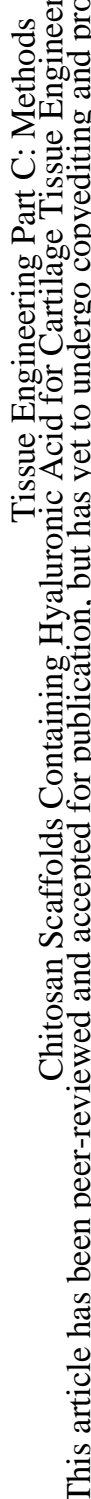


Page 37 of 37

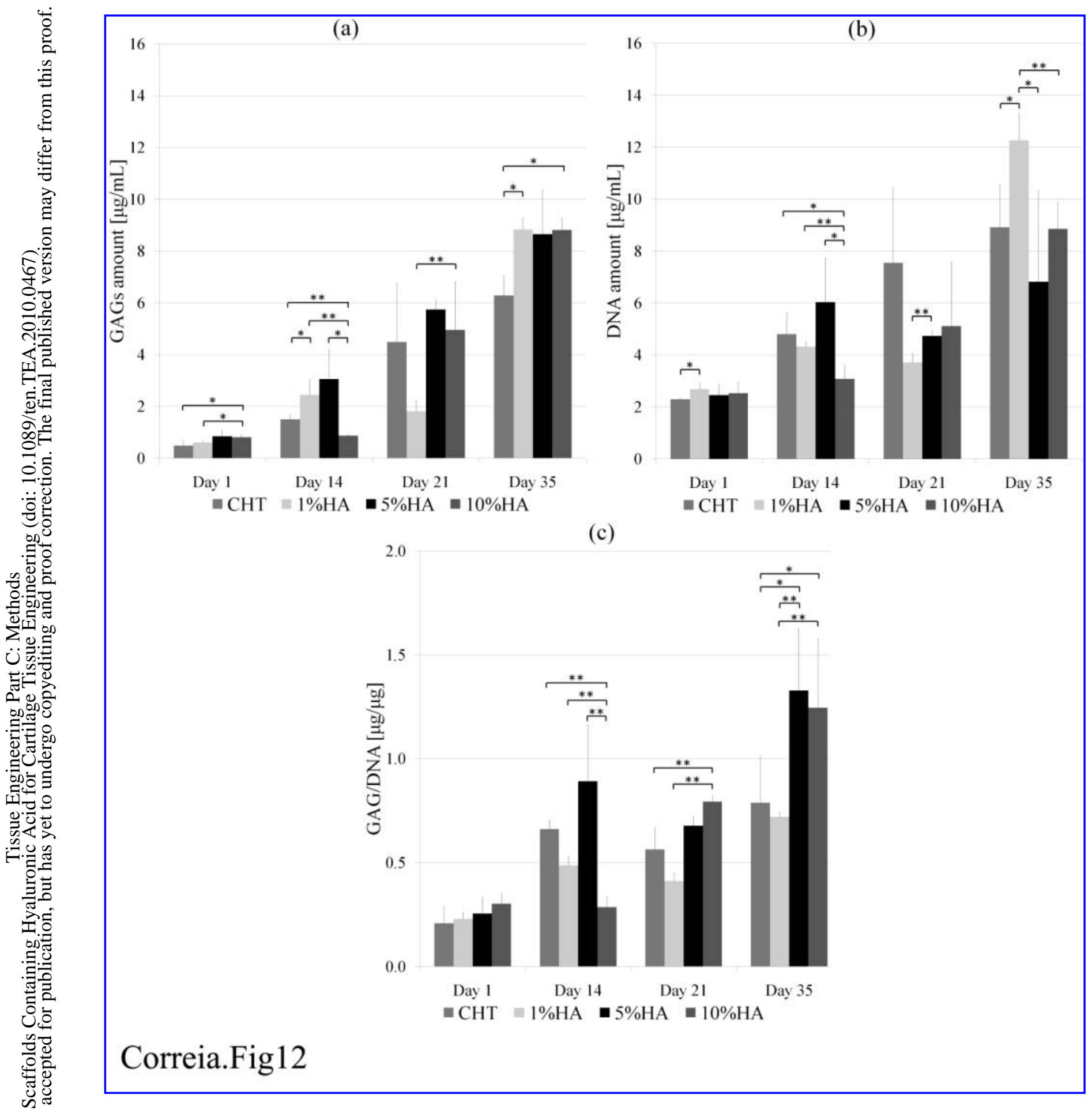

